\title{
ZONEAMENTO GEOGRÁFICO DOS GEOCOMPLEXOS DA BACIA HIDROGRÁFICA DO RIO TIBAGI/PR
}

\author{
Marcelo Gonçalves \\ Mestre em Geografia, Meio Ambiente e Desenvolvimento - Universidade Estadual de Londrina \\ marcelogeo@yahoo.com.br \\ Mirian Vizintim Fernandes Barros \\ mirianvizintim@gmail.com
}

\section{Resumo}

Objetivando propor mudanças na utilização dos recursos naturais da bacia hidrográfica do rio Tibagi, este estudo buscou trilhar um novo escopo para a ocupação deste território. Pautado na metodologia geossistêmica e tendo no relevo o seu eixo central, buscou-se uma análise integrada dos sistemas físicos, sócio-econômicos e bióticos que transformam o ambiente. Os dados levantados através do diagnóstico foram detalhados e sistematizados através de ferramentas de geoprocessamento. Foram realizados levantamentos de campo para validação das informações levantadas em fontes secundárias e para conhecimento da área de estudo, em especial as feições do relevo.

Palavras-chave: Bacia Hidrográfica, metodologia geossistêmica, geocomplexo geoprocessamento, Zoneamento Geográfico.

\section{INTRODUÇÃO}

A utilização dos recursos naturais pelo homem tem transformado a Terra mais do que qualquer outra atividade já vista nos últimos séculos. Isto gera uma aparente situação de crise ambiental e social.

Com a provável perda da capacidade produtiva do sistema econômico vigente e conseqüente deterioração dos recursos da Terra, devem-se repensar as maneiras de exploração dos recursos naturais.

A gestão do território, através de regulamentações e diretrizes, tenta buscar uma possível sustentabilidade para o desenvolvimento da sociedade, revendo as relações do homem com a natureza e implantando processos de planejamento e gestão ambiental e do território.

De acordo com Ross (2006), as relações sociedade-natureza são objetos da Geografia e esta deve desempenhar um importante papel para a produção do conhecimento humano e para a transformação desse conhecimento em benefícios para a humanidade.

Sendo a Geografia “disciplina que estuda as organizações espaciais", (Chistofoletti, 1999) nada melhor do que esta ciência para tentar buscar o equilíbrio entre a utilização dos recursos naturais e sua preservação.

Elhai (1968) citado por Troppmair (1989. pg. 99) diz que "A Geografia Física, de forma específica, focaliza os atributos espaciais dos sistemas naturais, particularmente na medida em que se relacionam com a humanidade". Partindo disso chegamos ao segmento denominado por Grigoriev como "estrato geográfico", definido pelos processos físicos e químicos e as morfologias dos materiais (ROSS, 2006).

Esse "estrato geográfico" pode ser considerado o local onde a relação entre natureza e sociedade se dá, onde as transformações decorrentes da ação antrópica são imediatamente percebidas e onde os processos 
da dinâmica ambiental são observados com maior freqüência. É então possível estabelecer o relevo como eixo central deste estudo, entretanto, sem deixar de integrar os demais componentes da paisagem, pois,

as formas de relevo podem transmitir a falsa idéia de que são componentes independentes na paisagem. $\mathrm{Na}$ verdade, elas e os demais componentes do ambiente estão interligados, promovendo ações, muitas vezes induzidas por influências mútuas, que, em maior ou menor intensidade, agem no sentido de criar uma fisionomia que reflete, no todo ambiental ou em suas partes, um ou mais ajustes alcançados (MARQUES, 2003, pg. 27).

Troppmair (1989, pg. 99) afirma que "não podemos estudar o solo, o clima, a água, a vegetação de forma isolada e sim deve prevalecer a visão integrada e sistêmica".

A postura em focalizar as questões geográficas sob a visão sistêmica favoreceu e dinamizou o desenvolvimento dos estudos geográficos. A aplicação da teoria geral dos sistemas ("General systems theory") nos estudos geográficos foi desenvolvida

nos Estados Unidos, devendo-se a R. Defay, em 1929, e a Ludwig Von Bertalanffy, a partir de 1932, as primeiras aplicações na termodinâmica e na biologia. [...] A aplicação da teoria dos sistemas aos estudos geográficos serviu para melhor focalizar as pesquisas e para delinear com maior exatidão o setor de estudo desta ciência, além de propiciar oportunidade para reconsiderações críticas de muitos dos seus conceitos, (CHISTOFOLETTI, 1979, pg. 12).

Nos sistemas ambientais, dois componentes básicos entram em sua estruturação e funcionamento, o sistema ambiental físico e o sistema sócio-econômico.

De acordo com Christofoletti (1999, pg. 37) os sistemas ambientais físicos "representam a organização espacial resultante da interação dos elementos componentes físicos e biológicos da natureza", além disso, "possuem expressão espacial na superfície terrestre, funcionando através da interação areal dos fluxos de matéria e energia entre seus componentes". Os componentes físicos da natureza são representados por aspectos como clima, geologia, geomorfologia, solos, águas, já os componentes biológicos são representados pela vegetação e animais.

Porém, como colocam Veado \& Troppmair (2001, p. 382) "os geossistemas são dinamizados por incontáveis fatores ambientais, mas o uso da terra sobressai-se como o mais importante, porque é ele que modifica constantemente a organização espacial do território". Portanto, tal estudo, se torna um dos passos mais importantes para a realização de uma análise geossistêmica.

Assim, esse relacionamento entre os sistemas naturais e ação antrópica é um dos elementos básicos para o planejamento eficiente, tanto ambiental quanto territorial, sendo que a Geografia agrega conhecimentos satisfatórios para este fim.

Neste sentido, utilizando-se da análise sistêmica, a Geografia procura estudar o espaço geográfico e criar meios de organizá-lo e planejá-lo. (VEADO \& TROPPMAIR, 2001). A metodologia geossistêmica pode ser norteadora deste processo de planejamento, pois consegue sistematizar os componentes da paisagem em unidades representativas e homogêneas, permitindo sua delimitação e mapeamento, agregando os componentes próprios para as mais variadas análises.

Sotchava, no início da década de 1960, propôs o nome de geossistema para o conjunto de componentes, processos e relações dos sistemas que integram o meio ambiente físico, em que pode ocorrer exploração biológica, e podem ser definidos como:

sistemas naturais, de nível local, regional ou global, nos quais o substrato mineral, o solo, as comunidades de seres vivos, a água e as massas de ar, particulares às diversas subdivisões da superfície terrestre, são interconectados por fluxos de matéria e de energia, em um só conjunto (SOTCHAVA 1977, p. 10). 
O autor introduziu o termo geossistema na literatura soviética para estabelecer uma tipologia aplicável aos fenômenos geográficos, enfocando aspectos integrados dos elementos naturais numa entidade espacial (CHRISTOFOLETTI, 1999).

Bertrand (1972, p.2) define paisagem, e em escala de análise diferente o geossistema, como "situado numa determinada porção do espaço, sendo o resultado da combinação dinâmica, portanto instável, de elementos físicos, biológicos e antrópicos, que fazem da paisagem um conjunto único e indissociável, em perpétua evolução".

Para Troppmair (1989, p. 99) é "um espaço que se caracteriza pela homogeneidade dos seus componentes, suas estruturas, fluxos e relações que, integradas, formam o sistema do ambiente físico onde há exploração biológica".

Observa-se nas três definições de geossistema, que cada autor prioriza um elemento específico dentro da mesma metodologia. Aparentemente, Sotchava prioriza as subdivisões da superfície terrestre, ou seja, o relevo. Bertrand da maior enfoque às questões antrópicas, em especial a dinâmica e evolução do uso e ocupação do solo. Já Troppmair trabalha com maior ênfase a exploração biológica do espaço, em especial as condicionadas pela vegetação. Em comum, nota-se a grande influência da Geografia Física nas definições dos três são pensadores.

A Geografia Física, cuja intenção, como afirma Ross (2006, p. 27), "é de contribuir para a promoção de melhorias/otimização dos ambientes naturais", pode ser considerada uma premissa do que se coloca hoje como foco principal para o desenvolvimento sustentável.

Assim, este trabalho teve como objetivo propor uma utilização racional dos recursos da bacia hidrográfica do rio Tibagi através de uma nova forma de uso e ocupação do solo da bacia. Para isso as questões ambientais e geográficas foram analisadas sob uma perspectiva sistêmica, ou seja, buscou na teoria geossistêmica trilhar um novo escopo para a ocupação deste território.

Tendo o relevo como eixo central buscou-se uma análise integrada dos sistemas ambientais que transformam o ambiente. O relevo foi definido para delinear este estudo por se tratar do palco onde acontecem quase todas as transformações da sociedade e da natureza, e, a bacia hidrográfica definida como unidade de gestão da paisagem e do geossistema.

Inicialmente foi realizado um diagnóstico ambiental da Bacia Hidrográfica do Rio Tibagi que serviu de base para as análises dos geocomplexos e para a elaboração do zoneamento geográfico, sendo que esta etapa se deu através de levantamentos em fontes secundárias, além de observações de campo. Os dados levantados foram armazenados em ambiente SIG e trabalhados através de ferramentas de geoprocessamento.

Por fim, estabeleceu-se um zoneamento como forma de sistematizar os conhecimentos sobre a natureza e a sua estrutura, sobre os elementos que a compõe, considerando a importância ecológica, as limitações e as fragilidades dos ecossistemas, criando uma proposta de novas zonas para utilização mais racional dos recursos naturais.

\section{ÁREA DE ESTUDO E MÉTODOS UTILIZADOS}

A bacia hidrográfica do rio Tibagi localiza-se na parte nordeste do estado do Paraná, entre os paralelos

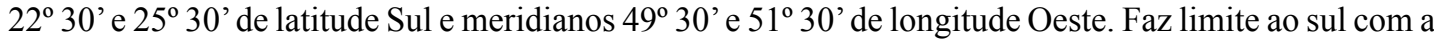
bacia do rio Iguaçu, ao norte com a bacia do rio Paranapanema, a oeste com a bacia do rio Ivaí, e Pirapó e a leste com as bacias dos rios Ribeira, Itararé e Cinzas (Figura 1). Tem comprimento médio de $320 \mathrm{~km}$ e largura média de $78 \mathrm{~km}$ e uma área aproximada de $24.715 \mathrm{~km}^{2}$ (COPEL, 1997).

Revista da ANPEGE. v. 6, 2010 (jan./dez.) 


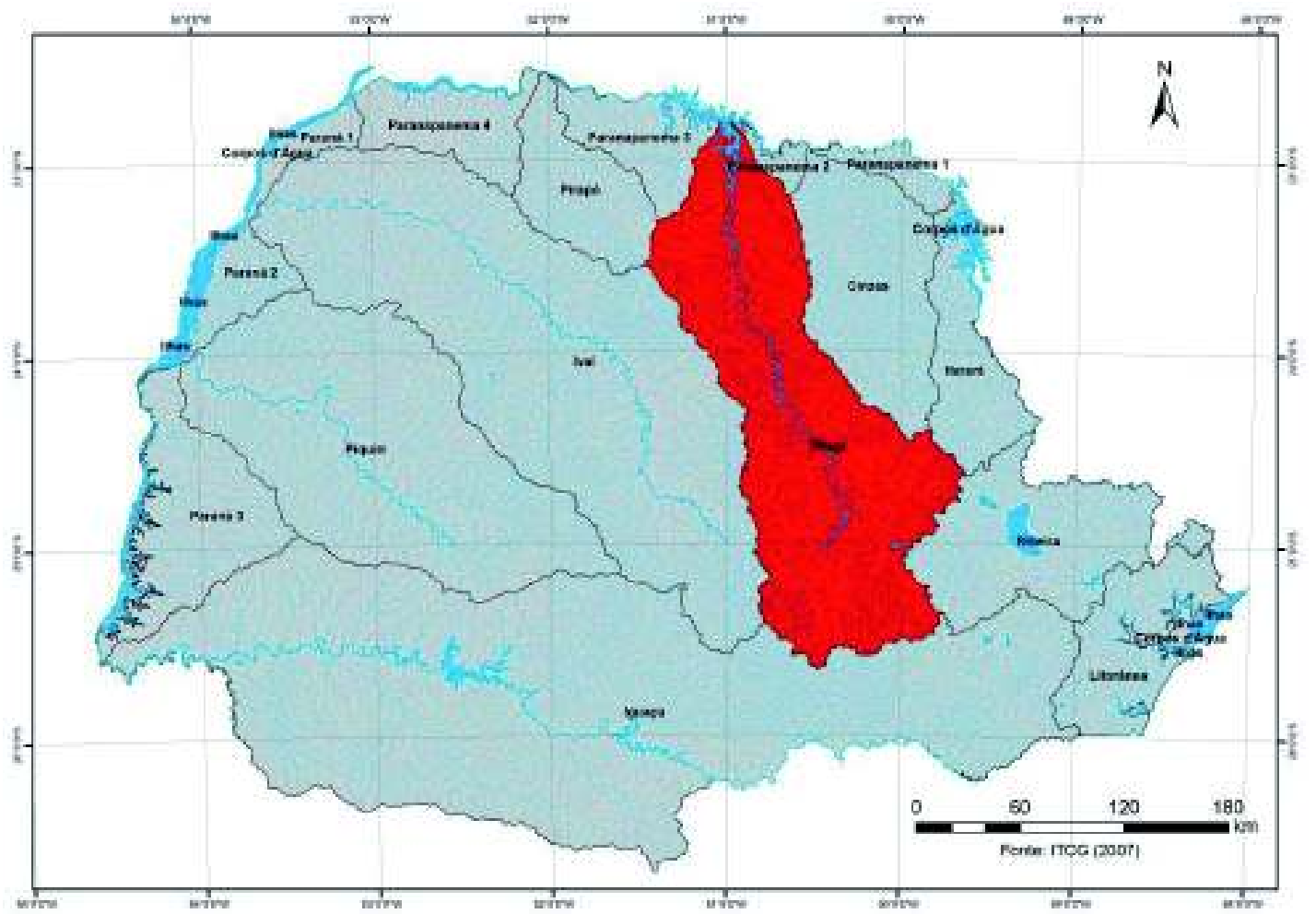

Figura 1 - Localização da Bacia Hidrográfica do Rio Tibagi/PR.

ORG: Autor

Para subsidiar a proposta de zoneamento e delimitar os geocomplexos foi realizada uma análise dos sistemas ambientais físicos, biológicos e socioeconômicos decorrentes de uma combinação de informações marcadas pelas características: do relevo; geologia; pedologia; águas subterrâneas e superficiais; fitogeografia; uso e ocupação do solo, e; aptidão agrícola dos solos.

Estes dados foram trabalhados em ambiente SIG (Sistema de Informações Georreferenciadas), utilizando ferramentas de geoprocessamento dos programas SPRING/INPE e ArcGIS ${ }^{\circledR}$ para recorte, combinações, cruzamentos, qualificação e quantificação das informações.

Utilizou-se para isso uma escala de análise das bases cartográficas de 1:250.000 e as informações foram baseadas em algumas obras, com destaque para: CMNP (1975); IBGE (1992); SUDERHSA (1998); EMBRAPA (1999); Mendonça (2000 e 2002); Veado \& Troppmair (2001); MINEROPAR (2005 e 2006); Torezan (2002); Soares \& Medri (2002); Martins (2002); Ross (2006); ITCG (2007); além de observações de campo.

Para a delimitação dos geocomplexos e geofácies foram utilizadas a metodologia e a taxonomia proposta por Bertrand no artigo, intitulado Paysage e geographie physique globale (1968), nele o autor 
definiu as relações entre paisagem e geossistema, salientando que os estudos de aspectos da paisagem se apóiam na delimitação formado por unidades homogêneas e que se encaixam umas nas outras, propondo um sistema de classificação que comporta seis níveis divididos em unidades superiores (zona, domínio e região) e inferiores (geossistema, geofácies e geotopo).

Todos os dados foram armazenados no SIG e manipulados de forma a apresentar as características dos geocomplexos e geofáceis.

Assim, pode-se observar que em termos geomorfológicos a bacia do Tibagi se mostra bastante heterogênea por abranger áreas em três planaltos do Estado, o Primeiro Planalto, o Segundo Planalto e o Terceiro Planalto (Figura 2).

O Primeiro Planalto Paranaense, de acordo com o Atlas Geomorfológico da MINEROPAR (2006), está inserido na unidade morfo-estrutural do Cinturão Orogênico do Atlântico, delimitado pelas áreas em que ocorrem as litologias de idade Proterozóica superior do Grupo Açungui e Intrusivas Graníticas e pelas rochas metavulcânicas do Grupo Castro, faixas litológicas que se estendem na direção nordeste-sudoeste. Apresenta uma relativa uniformidade e é representado pelos Planaltos de Castro, do Alto Ribeira e do Alto Jaguariaíva, com ampla predominância na bacia do rio Tibagi do Planalto de Castro. O relevo do Primeiro Planalto é montanhoso e orientado por uma sucessão de espigões alongados e vales em "V" profundos (Stipp, 2000b).

O Segundo e o Terceiro Planalto Paranaense estão inseridos na Bacia Sedimentar do Paraná, uma extensa depressão deposicional situada no centro-leste do continente sul-americano, cobrindo cerca de $1.600 .000 \mathrm{~km}^{2}$. Destes, $1.000 .000 \mathrm{~km}^{2}$ localizam-se em território brasileiro e no Estado do Paraná cerca de $130.000 \mathrm{~km}^{2}$. Trata-se de uma bacia intracratônica simétrica, preenchida com quase $5.000 \mathrm{~m}$ de sedimentos paleozóicos, mesozóicos, lavas basálticas e, localmente, rochas cenozóicas.

O Segundo Planalto Paranaense é representado pelas sub-unidades morfo-esculturais dos Planaltos de São Luiz do Purunã, do Alto do Ivaí, de Ortigueira, de Santo Antonio da Platina, de Jaguariaíva, de Tibagi, de Ponta Grossa, do Guatá, de São Mateus do Sul, de Irati, de Prudentópolis e os Residuais da Formação Teresina, com predominância do Planalto de Ponta Grossa (MINEROPAR, 2006). É constituído por relevos tabulares, que formam cuestas e plataformas estruturais mais dissecadas, apresentando suave inclinação sub-horizontal para oeste (STIPP, 2000b).

O Terceiro Planalto Paranense é representado pelas sub-unidades morfo-esculturais dos Planaltos de Foz do Areia, de Apucarana, de Londrina, do Médio Paranapanema e de Maringá, os quais, juntos, representam cerca de $27,96 \%$ da área da bacia do rio Tibagi, com ampla predominância do Planalto de Londrina (MINEROPAR, 2006). Apresenta-se relativamente baixo e cortado por platôs isolados e mesetas, com altitudes que constituem divisores de águas secundários e suaves colinas e platôs (STIPP, 2000b).

Ainda apresentam-se como sub-unidades morfo-esculturais as Planícies Fluviais, constituídas por sedimentos recentes de areias, siltes, argilas e cascalhos e ocorrentes em praticamente todas as unidades morfo-esculturais do Cinturão Orogênico do Atlântico e da Bacia Sedimentar do Paraná, (MINEROPAR, 2006).

A variação de altitude acentuada demonstra que nas cabeceiras da bacia encontram-se valores em torno de $1.200 \mathrm{~m}$ enquanto na foz a variação é de 250 a $300 \mathrm{~m}$ sendo que as regiões mais altas estão localizadas nas áreas de transição entre o Primeiro e o Segundo Planalto, região esta conhecida como Escarpa Devoniana.

As análises da vegetação original e atual e o uso do solo foi o ponto de partida para o estudo da ocupação territorial e da proposta de zoneamento.

Revista da ANPEGE. v. 6, 2010 (jan./dez.) 

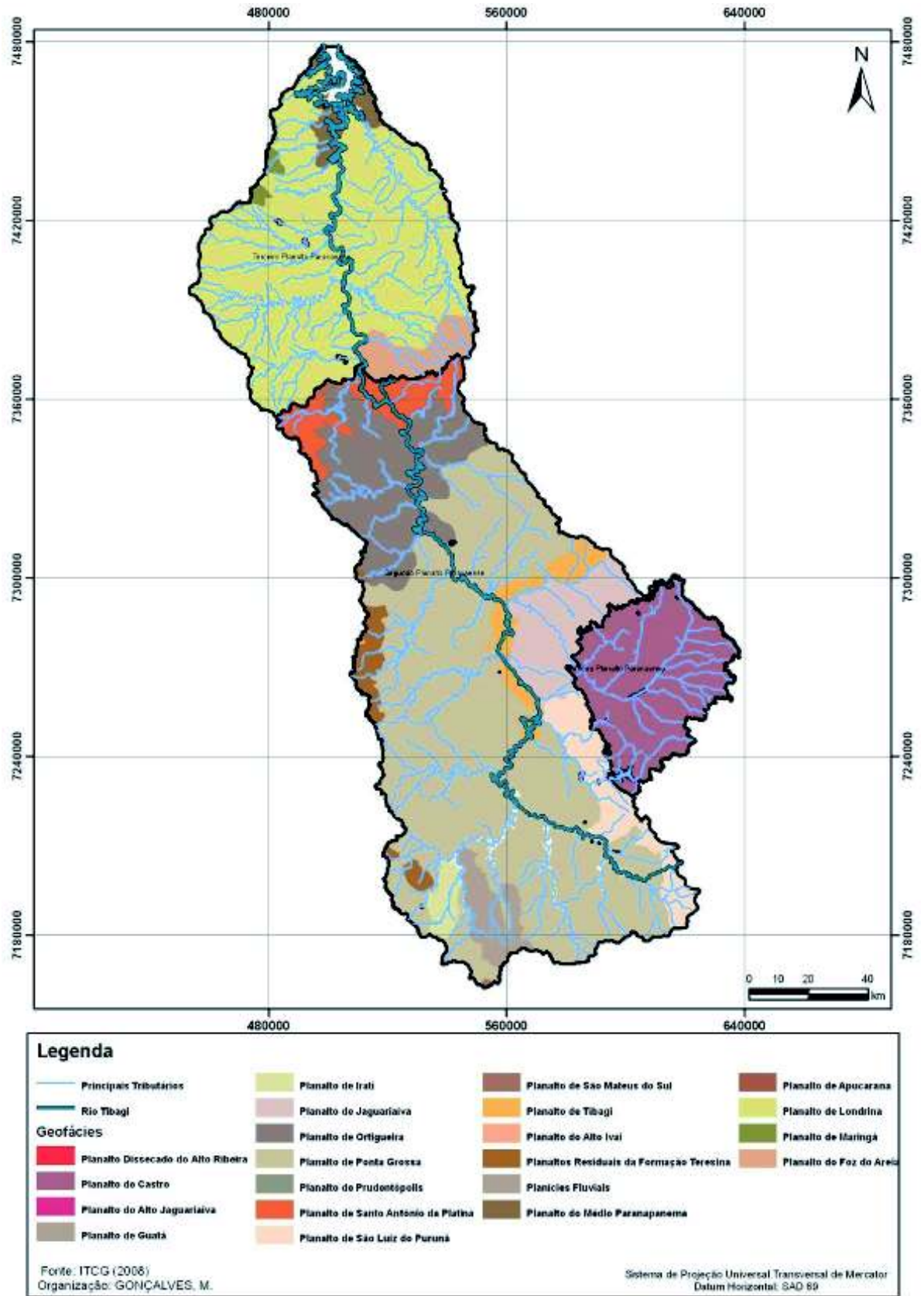

Figura 2 - Unidades Geomorfológicas da Bacia do Rio Tibagi/PR.

Fonte: Gonçalves (2009) 
Apesar da vegetação primária quase ser inexistente nos dias atuais, serviu como premissa para o estudo atual da vegetação. Afirmam Veado \& Troppmair (2001, p. 383) que "para conhecer a sucessão atual é necessário, antes, compreender como se dava a sucessão original, porque os processos, praticamente, são os mesmos". Apesar da ressalva que os processos propriamente ditos continuam os mesmos de antes, porém, a sua ação intensificou-se ou reduziu-se devido às transformações introduzidas pelas atividades humanas, que alteraram os fluxos de energia e matéria dos geocomplexos.

De acordo com os mapas criados e modificados a partir de dados do IPARDES (2005) e baseado em cálculos realizados através de ferramentas de geoprocessamento, atualmente, a bacia hidrográfica do rio Tibagi, apresenta um remanescente de $4,3 \%$ da vegetação original. Deste total, $37 \%$ são de Floresta Estacional Semidecidual, 36\% de Floresta Ombrófila Mista e 27\% de áreas de Campos Naturais.

Os dados históricos e sócio-econômicos serviram para estabelecer os recortes espaciais, definindo uma divisão por áreas com características comuns, tomando como base os usos predominantes.

Segundo Veado \& Troppmair (2001, p. 382) "os geossistemas são dinamizados por incontáveis fatores ambientais, mas o uso da terra sobressai-se como o mais importante, porque é ele que modifica constantemente a organização espacial do território". Portanto, tal estudo, se torna um dos passos mais importantes para a realização de uma análise geossistêmica.

Para esta análise da transformação da natureza da bacia hidrográfica do rio Tibagi, onde, em pouco mais de cinqüenta anos, a maioria dos espaços naturais se tornaram agropecuários, foram utilizados dados de uso do solo de 1989/1990 e de 2000/2001 (Figura 3) além de dados de aptidão agrícola e áreas com potencial de degradação dos solos. Também foram realizadas observações in loco para verificação dos padrões de uso do solo. Nas análises destes materiais foram considerados os padrões de uso do solo de cada geocomplexo da bacia do rio Tibagi.

O padrão geral de uso do solo da bacia do rio Tibagi nos anos de 1989/1990, observado nos estudos realizado pelo IPARDES em 1990, disponível em ITCG (2007), é o mesmo encontrado atualmente, ou seja, predominantemente agropecuário, as diferenças estão em algumas áreas que, de acordo com as mudanças no padrão de produção agrícola, alteraram também seus usos. Nos anos de 1989/1990 as áreas ocupadas por pastagens eram mais significativas, assim como as áreas de matas naturais e as áreas agrícolas possuíam um padrão de produção diferente dos dias de hoje, uma vez que o grande avanço tecnológico no campo ainda não estava tão consolidado como no final da década de 1990. Assim, os problemas de erosão causados pelo grande número de áreas agrícolas que ficavam com o solo exposto nas entressafras eram maiores do que atualmente, onde o plantio direto, sem a exposição direta do solo, está em praticamente todas as propriedades de produção de grãos do Paraná. Todos estes fatores foram essenciais para o zoneamento geográfico da bacia.

\section{ZONEAMENTO GEOGRÁFICO}

O zoneamento apresentado é uma proposta sustentada na teoria dos sistemas, aplicando por Bertrand no artigo intitulado "Paysage e geographie physique globale" (1968), criando uma sistematização dos conhecimentos sobre a natureza e a sua estrutura, sobre os elementos que a compõem, a maneira como uns influenciam os outros, o papel e a função de cada um deles e como o homem modifica o ambiente, produzindo modificações na morfologia e criando novas estruturas na organização espacial do território.

Esta proposta se assemelha a um Zoneamento Ecológico-Economico (ZEE), porém, optou-se pela denominação de Zoneamento Geográfico pela ausência de algumas etapas que configuram o ZEE, principalmente o caráter de participação popular e de multidisciplinaridade existente nos ZEEs. Além

Revista da ANPEGE. v. 6, 2010 (jan./dez.) 


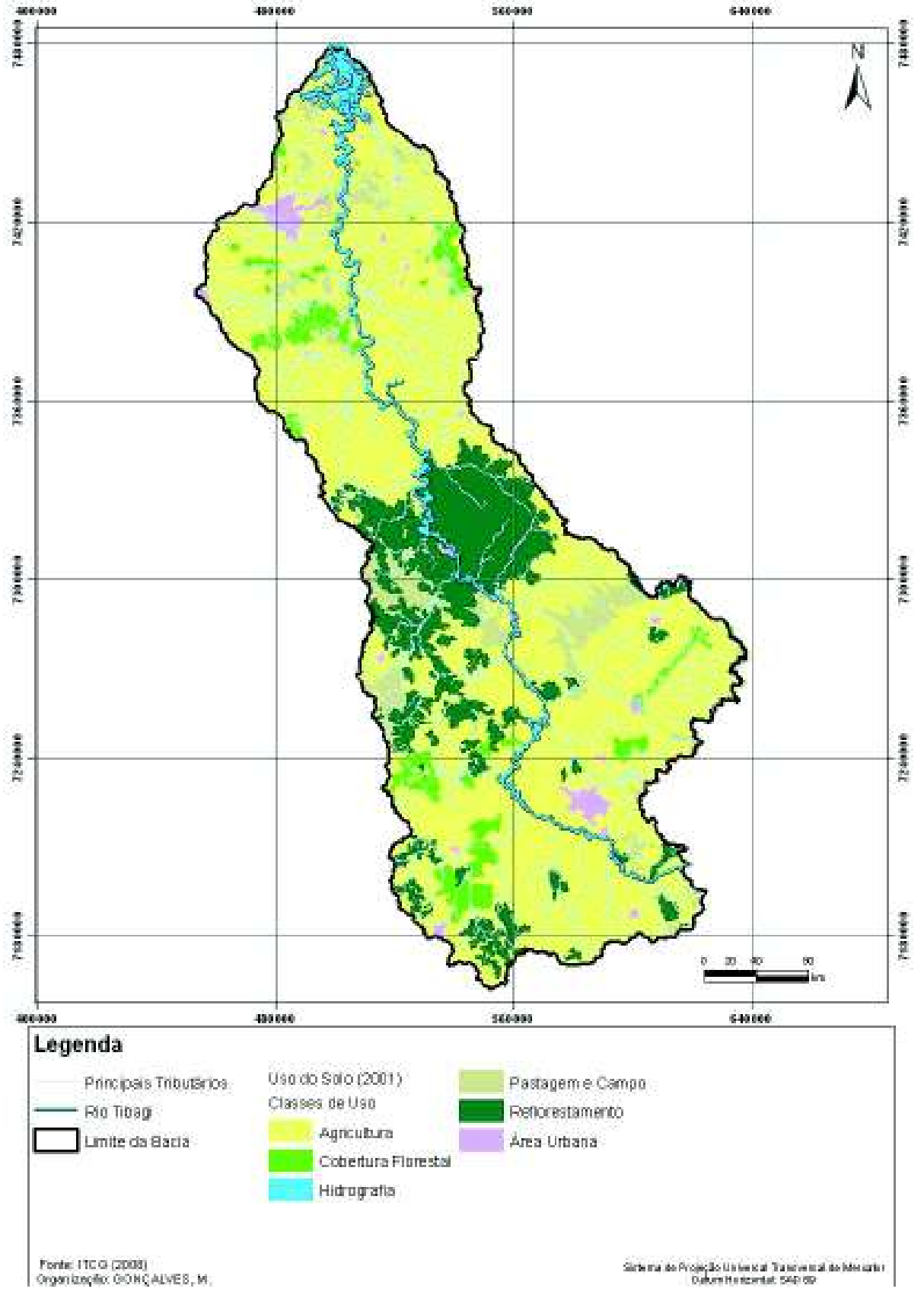

Figura 3 - Uso do Solo da Bacia Hidrográfica do Rio Tibagi/PR (2001).

ORG: Autor. 
disso, esta servirá mais como subsídio para um futuro ZEE do que como o próprio instrumento político e técnico de planejamento.

As diretrizes gerais e específicas do zoneamento devem estar de acordo com as metas a serem atingidas e que são de três ordens distintas (ROSS et al, 1995):

- Ações corretivas e preventivas para proteger ou conservar os ambientes naturais e valorizar a cultura da população envolvida;

- Programas de incentivo para incrementar as atividades econômicas compatíveis, de um lado, com a fragilidade dos sistemas ambientais naturais e dos padrões culturais, sociais e econômicos das populações envolvidas, e, de outro, com a capacidade de suporte dos recursos naturais renováveis;

- Meios institucionais para definir uma articulação político-institucional de gestão integrada, implementada pelos órgãos de Estado (Municípios, Estados e União).

A proposta de zoneamento da bacia hidrográfica do rio Tibagi conta com oito zonas distintas separadas de acordo com as diretrizes ambientais legais, aptidões tipos de usos do solo levantados a partir do diagnóstico. São áreas de preservação permanente, segundo o Código Florestal, unidades de conservação, áreas urbanas, áreas de uso agrícola com aptidões e restrições de uso e áreas inaptas à agricultura.

Devido às características dos solos e à predominância agrícola do uso do solo da bacia, o fator base na definição das zonas foi a aptidão agrícola do solo, porém, todas as outras zonas propostas, devido às características legais e importância ecológica, cultural ou natural se sobrepõem à aptidão, assim, as zonas são propostas para priorizar o desenvolvimento sustentável da bacia, buscando equilíbrio entre o uso e a proteção dos recursos naturais.

Constam nesta proposta desde zonas com enfoque ao uso agropecuário até zonas de proteção integral e zonas especiais de conservação:

- ZAPP (Zona de Áreas de Preservação Permanente) - são zonas que contém as áreas de preservação permanente dispostas linearmente nas margens dos rios, segundo o Código Florestal. Devido à escala de análise, foram mapeadas apenas as áreas de cursos hídricos com largura superior a 50 metros.

- $\quad$ ZPIUS (Zona de Proteção Integral ou Uso Sustentável) - são zonas que representam as unidades de conservação existentes na bacia, foram divididas em "Proteção Integral" (PI) e "Uso Sustentável" (US), de acordo com as categorias de enquadramento destas áreas. Fazem parte desta zona as unidades de conservação das diferentes esferas: Estadual de Uso Sustentável; Estadual de Proteção Integral; Federal; Municipal, e Reservas Particulares ou RPPN's (Reservas Particulares do Patrimônio Natural).

- ZURB (Zona Urbana) - são as zonas representadas pelas áreas urbanas dos municípios, que totalizam 46 áreas inseridas total ou parcialmente na bacia.

- ZAUA (Zona Apta ao Uso Agrícola) - são zonas com boa ou regular aptidão agrícola, sem grandes restrições ou problemas de erosão, excesso hídrico, com algumas áreas com problemas de fertilidade e susceptibilidade a erosão, sendo preciso um manejo adequado do solo. No geral, são áreas onde podem ser praticados quaisquer usos agropecuários, com os devidos cuidados no manejo do solo e nas práticas agrícolas.

- $\quad$ ZIUA (Zona Inapta ao Uso Agrícola) - são zonas inaptas ao uso agrícola por fatores relacionados ao tipo de solo, declividade do terreno e localização em áreas úmidas. Por conta destes fatores, estas áreas possuem potencial elevado de erosão e excesso hídrico e não devem ser utilizadas para fins agrícolas, a não ser com práticas muito eficientes de conservação do solo.

Revista da ANPEGE. v. 6, 2010 (jan./dez.) 
- $\quad$ ZINDG (Zona Indígena) - são áreas de reserva indígenas, que possuem toda uma restrição de uso pela comunidade externa à indígena e deve ser fiscalizada, especialmente na questão fundiária, fora isso, deve ter um manejo adequado com os tipos de solo e declividade do terreno.

- $\quad$ ZUE (Zona de Uso Especial) - esta zona foi proposta por ser uma área de recarga do Aqǘfero Guarani, uma importante reserva estratégica de água da América do Sul, o uso do solo nestas áreas deve ser restritivo, especialmente para atividades com potencial de poluição do solo e das águas através de aplicação e despejo de produtos químicos.

- $\quad$ ZRUA (Zona Restrita ao Uso Agrícola) - são áreas que possuem algum tipo de restrição de uso quanto a aptidão do solo, geralmente são áreas que possuem restrição quanto a problemas de erosão, fertilidade, mecanização e excesso hídrico, sendo necessário um manejo adequado deste solo.

Para cada geocomplexo, foram definidas zonas caracterizadas, em:

I - Geocomplexo do Primeiro Planalto Paranaense - subdividido em cinco zonas, representadas na figura 4:

- ZAPP - proposta de acordo com o Código Florestal, apesar de se restringir as matas ciliares, representa $0,23 \%$ do geocomplexo, ou seja, 585,32 ha de áreas lineares correspondente às delimitações feitas de acordo com a largura do rio. Estas áreas foram mapeadas nos principais rios de acordo com a escala aplicada ao estudo.

- ZPIUS - ocupa uma área de 21.750,08 ha, o que representa 8,67\% da área do geocomplexo. São representadas por sete unidades de conservação.

- Z ZURB - ocupam uma área de 1.714,94 ha que representam 0,68\% das áreas zoneadas, representando as cidades de Castro e Piraí do Sul.

- Z ZAUA - são áreas com aptidão agrícola dos solos boa ou regular e representam mais da metade do geocomplexo com uma área de $132.433,57$ ha, ou $52,81 \%$ do total de terras.

- $\quad$ ZIUA - representam $37,60 \%$ da área ou $94.290,21$ ha de áreas inaptas ao uso agrícola por problemas de erosão ou excesso hídrico, sendo que estas áreas estão situadas nos maiores declives e nas áreas úmidas do geocomplexo.

II - Geocomplexo do Segundo Planalto Paranaense - foram propostas oito zonas (Figura 5):

- $\quad$ ZAPP - representam 2,89\% ou $42.361,75$ ha de áreas lineares correspondente às delimitações feitas de acordo com a largura dos principais rios deste geocomplexo.

- ZPIUS - ocupa uma área de 257.190,84 ha, o que representa 17,55\% da área. São representadas por 26 unidades de conservação. Além destas, existe a APA da Escarpa Devoniana e o Parque Nacional dos Campos Gerais.

- ZURB - ocupa uma área de 17.294,07 ha que representam 1,18\% das áreas zoneadas, tendo nos municípios de Ponta Grossa e Telêmaco Borba as maiores áreas.

- ZAUA - são áreas com boa ou regular aptidão agrícola dos solos e representam quase metade do geossistema com uma área de $699.143,05$ ha, ou $47,72 \%$ do total de terras.

- $\quad$ ZIUA - correspondem $25,96 \%$ ou $380.340,82$ ha, são áreas com problemas de erosão ou excesso hídrico, e estão situadas especialmente nos maiores declives e em áreas úmidas.

- $\quad$ ZINDG - ocupam área de $4.558,18$ ha, ou $0,31 \%$ das terras e são habitadas por índios da etnia Kaingang distribuídos em três reservas: Apucaraninha, no município de Tamarana; Tibagy/Mococa e Quimadas, no município de Ortigueira. São áreas de proteção integral de administração Federal. 


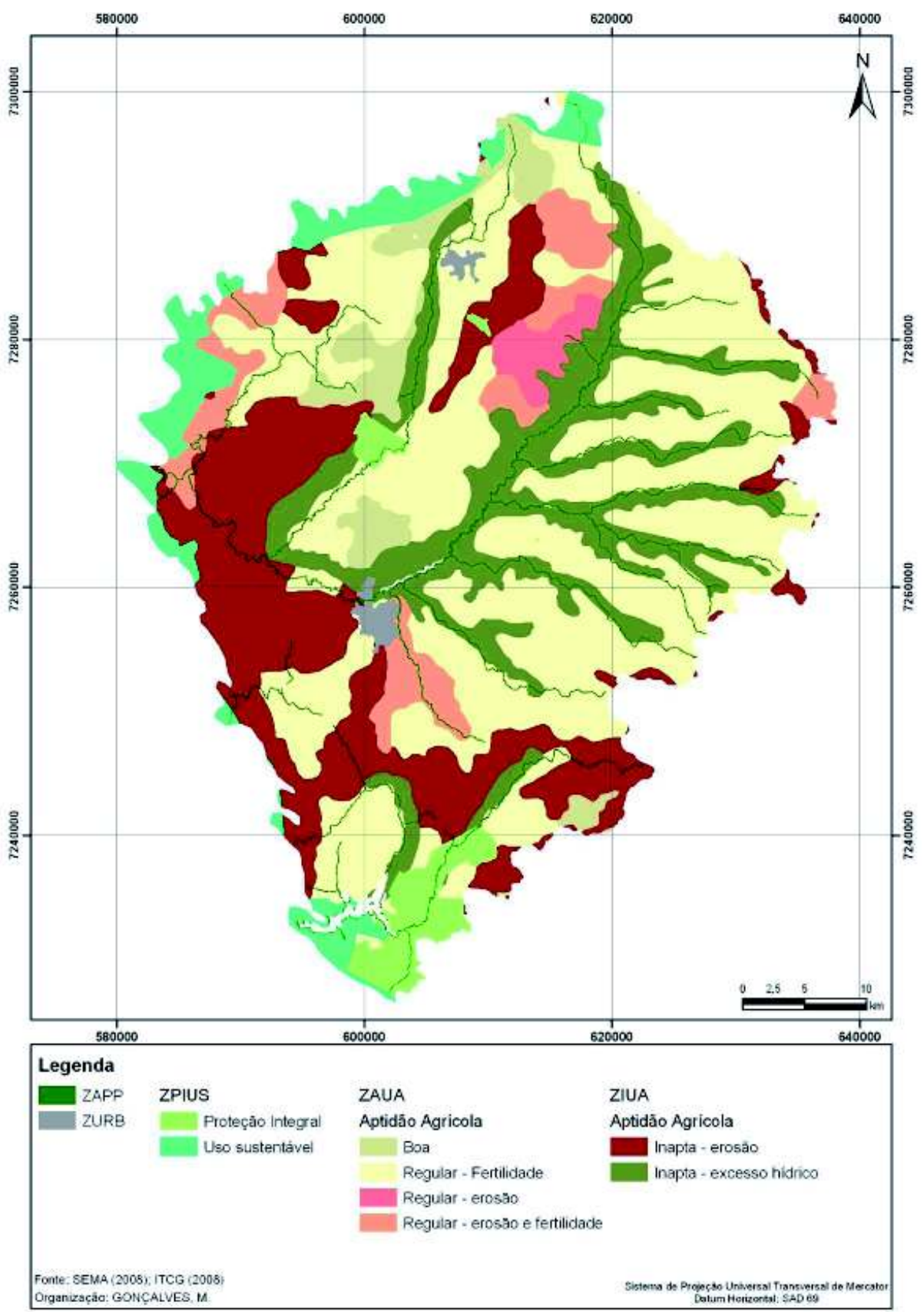

Figura 4 - Zoneamento Geográfico do Geocomplexo do Primeiro Planalto Paranaense Fonte: Gonçalves (2009). 
- $\quad$ ZUE - estão situadas na zona de transição entre o Segundo e o Terceiro Planalto Paranaense, e correspondem áreas de recarga do Aqüífero Guarani que representam uma área de 5.975,90, ou 0,41\% total.

- $\quad$ ZRUA - representam 3,98\% ou 58.333,96 ha das áreas do geocomplexo e possuem restrição de uso, principalmente, por problemas de erosão.

III - Geocomplexo do Terceiro Planalto Paranaense - também foram propostas oito zonas, apresentadas na figura 6.

- $\quad$ ZAPP - representa $6,40 \%$ ou $48.401,94$ ha de área linear. Grande parte desta área deve ser recuperada, já que apresenta alto grau de degradação mesmo quando compara as ZAPP dos geocomplexo I e II.

- $\quad$ ZPIUS - ocupa área de 1.931,88 ha, o que representa apenas 0,26\% da área do geossistema. São representadas por apenas quatro unidades de conservação.

- $\quad$ ZURB - ocupa área de $11.777,14$ ha que representam 1,56\% das áreas zoneadas, tendo nos municípios de Londrina a maior área de contribuição, este é o geocomplexo mais urbanizado da bacia, isto levando em conta que a maioria dos municípios, como Arapongas, Apucarana, Rolândia, Cornélio Procópio ocupam apenas metade da área desta unidade.

- $\quad$ ZAUA - são as de boa ou regular aptidão agrícola dos solos e representam mais metade do geossistema com uma área de 504.282,29 ha, ou 66,73\% do total de terras.

- $\quad$ ZIUA - corresponde a 21,19\% das terras, ou 160.137,60 ha, a maioria por problemas de erosão, sendo que estas áreas estão situadas especialmente onde há maiores declives e solos com textura mais arenosa.

- $\quad$ ZINDG - ocupam área de 8.739,48 há, ou 1,16\% das terras do geocomplexo Habitadas por índios da etnia Kaingang, Guarani e Xeta distribuídos em duas reservas: Barão de Antonina e São Jerônimo, ambas no município de São Jerônimo da Serra. São áreas de proteção integral de administração Federal.

- Z ZUE - estão situadas na zona de transição entre o Segundo e o Terceiro Planalto Paranaense, são áreas de recarga do Aqüífero Guarani e representam uma área de 13.707,84, ou 1,81\% total do geocompexo.

- $\quad$ ZRUA - representam $0,89 \%$, ou $6.715,78$ ha das áreas do geocomplexo e possuem restrição de uso, principalmente, por problemas de erosão.

As Zonas Geográficas propostas para a bacia do rio Tibagi, bem como as áreas de cada zona nos três geocomplexos são apresentados na Tabela 1 .

O zoneamento revela que a maior parte da bacia pode ser utilizada para atividades agrícolas sem grandes restrições de uso ou com restrições específicas. Nota-se também o grande percentual de áreas inaptas ao uso agropecuário, próximo a $25 \%$. Considerando que $20 \%$ da bacia deverão ser destinadas a criação de reservas legais, é necessário a realização de estudos para viabilizar a criação destas áreas nas zonas que são inaptas à agricultura, protegendo assim estes locais sem grandes prejuízos à produção agrícola da bacia.

Existem duas áreas em especial que merecem maior planejamento dos órgãos competentes que são as Zonas Indígenas e as Zonas de Uso Especial, cuja zona abrange a área de recarga do Aqüífero Guarani. São áreas especiais para preservação cultural e dos recursos hídricos subterrâneos da bacia. 


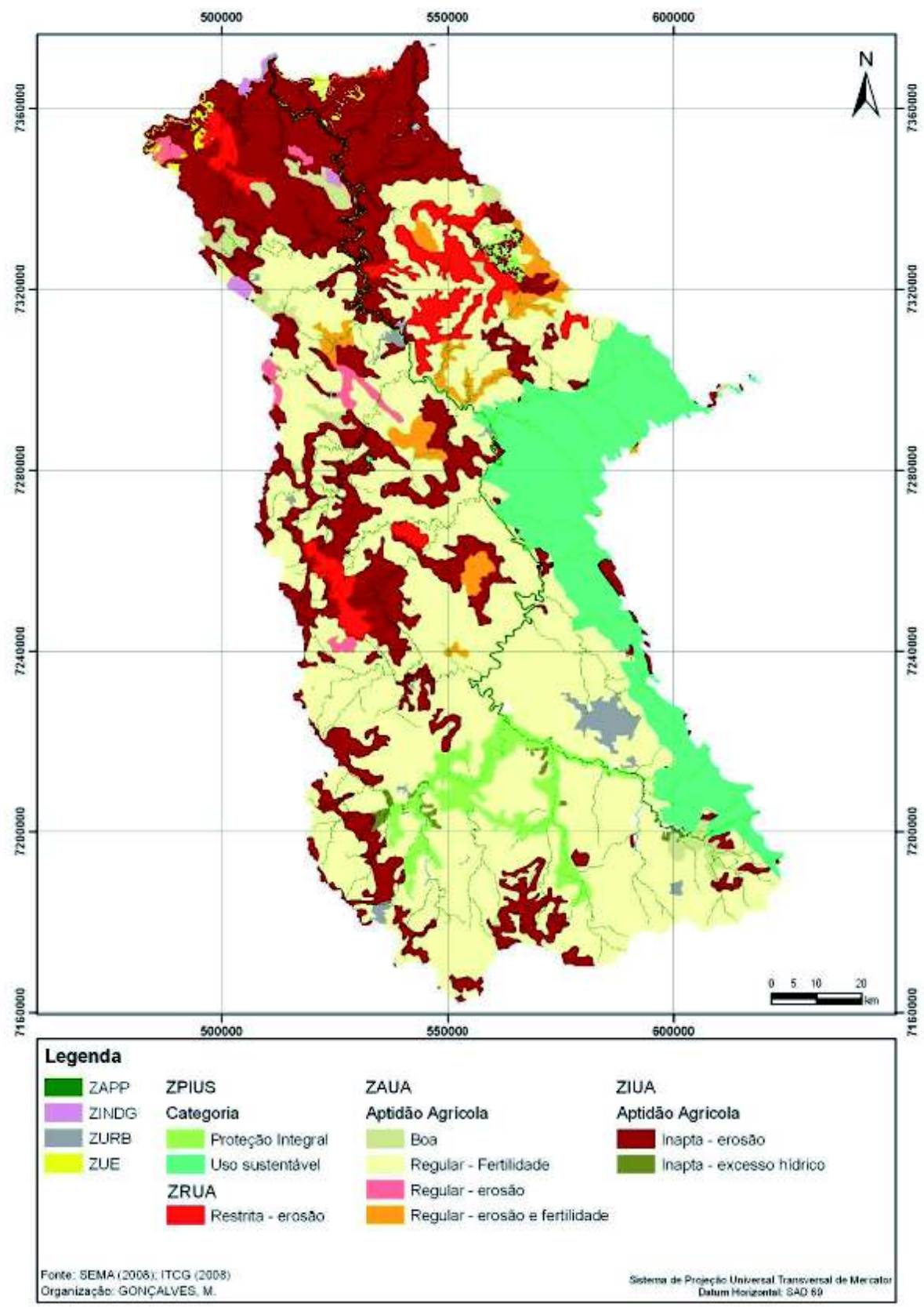

Figura 5 - Zoneamento Geográfico do Geocomplexo do Segundo Planalto Paranaense. Fonte: Gonçalves (2009). 


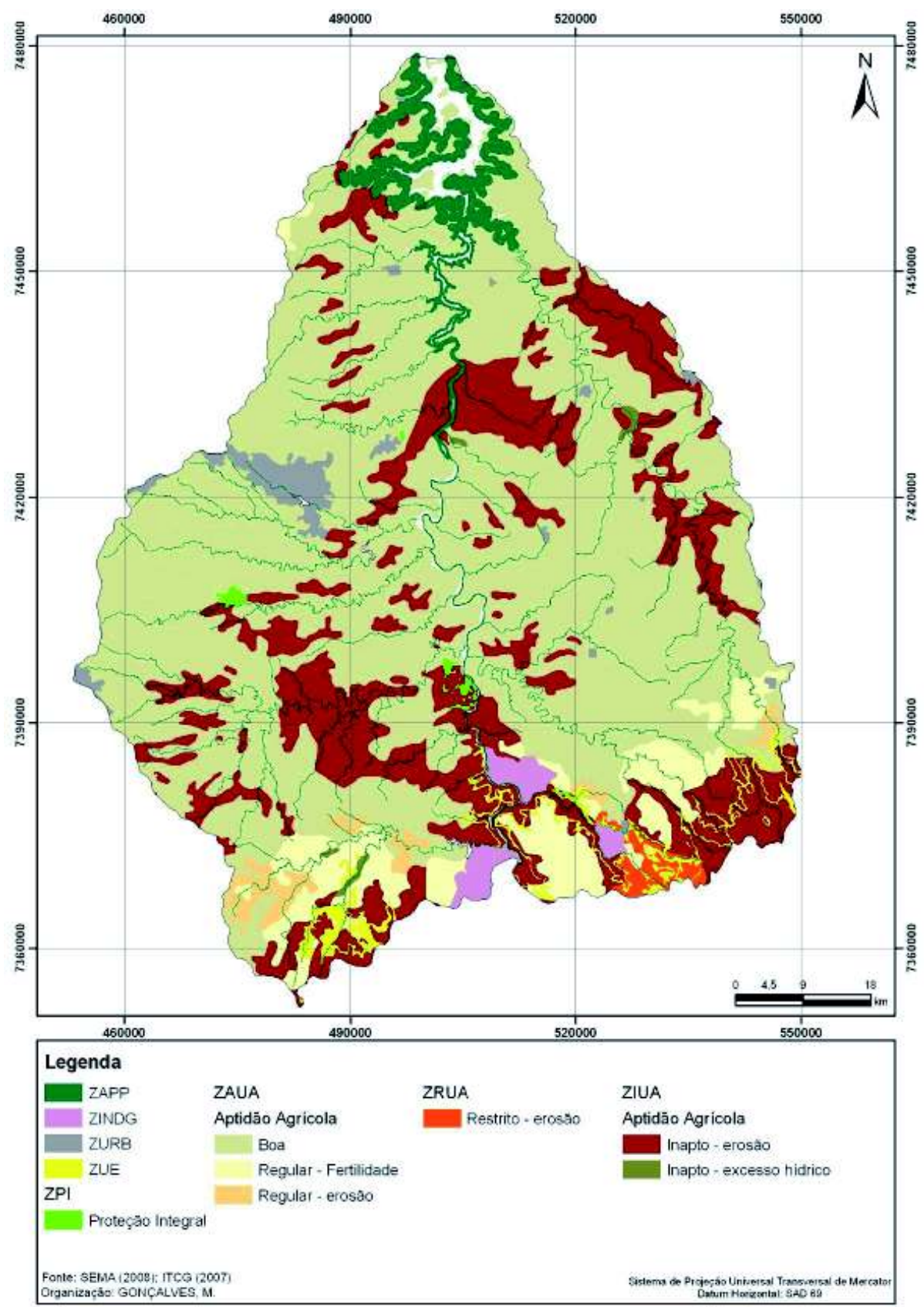

Figura 6 - Zoneamento Geográfico do Geocomplexo do Terceiro Planalto Paranaense Fonte: Gonçalves (2009) 
Tabela 1 - Zonas Geográficas propostas para a Bacia do Rio Tibagi

\begin{tabular}{|c|c|c|c|c|c|c|c|c|}
\hline ZONA & $1^{\circ}$ PLA- & $(\%)$ & $2^{\circ}$ PLANAL- & $(\%)$ & $3^{\circ}$ PLANAL- & $(\%)$ & TOTAL & $(\%)$ \\
\hline $\begin{array}{l}\text { ZPPPS } \\
\text { ZUNRB } \\
\text { ZAUA } \\
\text { ZINAA } \\
\text { ZUEA } \\
\text { ZRUA }\end{array}$ & $\begin{array}{r}\text { NALTO (ha) } \\
51.755,32 \\
1.714,94 \\
132.433,57 \\
94.290,21\end{array}$ & $\begin{array}{r}0,23 \\
8,67 \\
02,68 \\
57,61\end{array}$ & $\begin{array}{r}\text { TO (ha) } \\
42.361,75 \\
257.190,84 \\
699.144,07 \\
380.340,82 \\
4.558,18 \\
5.975,90 \\
58.333,96 \\
\end{array}$ & $\begin{array}{r}2,, 89 \\
17,55 \\
47,78 \\
25,96 \\
0,31 \\
0,41 \\
3,98 \\
\end{array}$ & $\begin{array}{r}\text { TO (ha) } \\
48.401,94 \\
11.937,88 \\
504.282,29 \\
160.137,29 \\
8.739,48 \\
13.707,84 \\
6.71,98 \\
\end{array}$ & $\begin{array}{r}6,40 \\
0,26 \\
1,56 \\
66,73 \\
21,19 \\
1,81 \\
0,89 \\
0.8\end{array}$ & 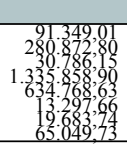 & $\begin{array}{r}3,70 \\
11,36 \\
14,25 \\
5,05 \\
25,68 \\
0,54 \\
0,80 \\
2,63\end{array}$ \\
\hline TAL & $250.774,12$ & 100 & $1.465 .198,57$ & 100 & $755.693,95$ & 100 & $2.471 .666,64$ & 100 \\
\hline
\end{tabular}

As demais áreas possuem legislação de uso especificada por Leis Federal ou Estadual e seus usos devem ser fiscalizados para que estas diretrizes específicas sejam seguidas.

\section{CONSIDERAÇÕES FINAIS}

A crescente adoção de metodologias que consideram os componentes da paisagem, incluindo o homem como parte atuante e modificadora do sistema ambiental, seja da paisagem natural ou cultural, indica uma mudança de paradigma gerado pelo grande acúmulo de experiências científicas que mostram a ineficiência de se entender o funcionamento de um sistema, seja ele geossistema ou ecossistema, apenas através do estudo de partes separadas de seus componentes, ignorando a inter-relação entre eles.

A utilização do geossistema se mostrou uma importante metodologia para o estudo dos sistemas ambientais, permitindo entender o dinamismo das inter-relações dos componentes que formam estes sistemas, ou seja, através das delimitações de feições do relevo e dos estudos integrados dos agentes que modificam e atuam sobre estes sistemas, foi possível entender, diagnosticar e propor alterações para um possível equilíbrio do sistema.

Para sistematizar estas diferentes informações e conjugá-las a fim de buscar uma integração entre as partes, as ferramentas de geoprocessamento se mostraram muito eficientes, especialmente para integrar e sobrepor as várias informações levantadas através do diagnóstico.

A proposta de zoneamento mostrou-se um bom instrumento de mudança das condições atuais de exploração dos recursos naturais e culturais, objetivando buscar o mais próximo possível da situação de equilíbrio, que garantirá a estabilidade dos sistemas por maior tempo.

Assim, esta proposta deve servir de instrumento para novas políticas de ocupação do solo da bacia hidrográfica do rio Tibagi. Servindo também como subsídio para a gestão dos recursos naturais, em especial a água. Para isto, devem ser formuladas leis específicas a fim de regulamentar os tipos de usos de cada zona proposta.

\section{REFERÊNCIAS BIBLIOGRÁFICAS}

BERTRAND, G. Paysage et géographie physique globale: esquisse méthodologique. Revue Géographique des Pyrénées et Sud-Ouest, v. 39, fasc. 3, p. 249-272, Phot.h.t. 1968.

BERTRAND, G. Paisagem e geografia física global: esboço metodológico. Cadernos de Ciências da Terra. São Paulo, v. 13, 1972 p. 1-27.

CHRISTOFOLETTI, A. Modelagem de Sistemas Ambientais. São Paulo: Edgard Blücher, 1999.

CHRISTOFOlETTI, A. Análise de Sistemas em Geografia. São Paulo: Hucitec - EDUSP, 1979.

Revista da ANPEGE. v. 6, 2010 (jan./dez.) 
CMNP, Companhia Melhoramentos Norte Do Paraná. Colonização e desenvolvimento do Norte do Paraná. 2. ed. São Paulo, 1975.

COPEL - Comapanhia Paranaense de Energia. Revisão da Divisão de Queda do Trecho Médio do Rio Tibagi. Curitiba, 1997.

EMBRAPA, Sistema Brasileiro de Classificação de Solos. $1^{\text {a }}$ Ed. Brasília: Embrapa, 1999.

GONÇALVES, M. Geossistemas da Bacia do Rio Tibagi: subsídios para a proposta de zoneamento geográfico. Dissertação de Mestrado. Departamento de Geociências, Mestrado em Geografia, Meio Ambiente e Desenvolvimento, Londrina: Edição do Autor, 2009.

IBGE, Instituto Brasileiro de Geografia e Estatística. Manual técnico da vegetação brasileira. Rio de Janeiro, 1992. 92p. (Manuais Técnicos em Geociências, 1).

IBGE, Instituto Brasileiro de Geografia e Estatística. Referências ambientais e socioeconômicas para o uso do território do Estado do Paraná: Uma contribuição ao zoneamento ecológico-econômico - ZEE. Curitiba, 2005.

ITCG, Instituto de Terras Cartografia e Geociências. Produtos Cartográficos. Disponível em: <http://www.itcg. pr.gov.br>. Acesso entre outubro e dezembro de 2007.

ITCG, Instituto de Terras Cartografia e Geociências. Produtos Cartográficos. Disponível em: <http://www.itcg. pr.gov.br>. Acesso entre maio e dezembro de 2008.

MARQUES, J. S. Ciência Geomorfológica. In: GUERRA, A. J. T. \& CUNHA, S. B. da. (Org). GEOMORFOLOGIA: uma atualização de bases e conceitos. $5^{\mathrm{a}}$ ed. Rio de Janeiro: Bertrand Brasil, 2003.

MARTINS, Tiago Damas. Expedição Ambiental - Relato Sociambiental: Nas águas do Tibagi. RODONORTE. 2002.

MENDONÇA, F. de A. A tipologia climática - Gênese, características e tendências. In: STIPP, N.A.F. (org). Macrozoneamento ambiental da bacia hidrográfica do rio Tibagi (PR). Londrina: Ed. UEL, 2000.

MENDONÇA, F. de A \& DANNI-OLIVEIRA I. M. Dinâmica atmosférica e tipos climáticos predominantes da bacia do rio Tibagi. In: A Bacia do Rio Tibagi. MEDRI, M. E. Londrina, 2002.

MINEROPAR, Minerais do Paraná S.A. CARTAS GEOLÓGICAS DO ESTADO DO PARANÁ - Escala 1:250.000, MINEROPAR, 2005.

MINEROPAR, Minerais do Paraná S.A. ATLAS GEOMORFOLÓGICO DO ESTADO DO PARANÁ - Escala 1:250.000. MINEROPAR, 2006.

ROSS, J. et al. Plano de Conservação da Bacia do Alto Paraguai. MMA. Brasília 1995.

ROSS, J. Ecogeografia do Brasil: subsídios para planejamento ambiental. São Paulo: Oficina de Textos, 2006.

SEMA, Secretaria de Estado do Meio Ambiente e Recursos Hídricos. Unidades de Conservação. Disponível em $<$ www.sema.pr.gov.br>. Acesso em outubro de 2008.

SOARES, F. S. \& MEDRI, M. E. Alguns aspectos da colonização da bacia do rio Tibagi. In: A Bacia do Rio Tibagi. Londrina (PR): M.E. Medri, 2002.

SOTCHAVA, V. B. O estudo de geossistemas. Instituto de Geografia. Universidade de São Paulo. São Paulo: Ed. Lunar, 1977.

SOUZA, B. I. \& SUERTEGARAY, D. M. A. Considerações sobre a Geografia e o Ambiente. Revista OKARA: Geografia em debate. V.1, n.1. João Pessoa, 2007. 
SUDERHSA, Superintendência de Desenvolvimento de Recursos Hídricos e Saneamento Ambiental. Atlas de Recursos Hídricos do Estado do Paraná. Curitiba, 1998.

STIPP, N.A.F. A Variedade Pedológica e suas Potencialidades. In: STIPP, N.A.F (org.). Macrozoneamento Ambiental da bacia hidrográfica do rio Tibagi (PR). Londrina: Ed. UEL, 2000a.

STIPP, N.A.F. A. Unidades Geológicas - Geomorfológicas. In: STIPP, N.A.F (org.). Macrozoneamento Ambiental da bacia hidrográfica do rio Tibagi (PR). Londrina: Ed. UEL, $2000 \mathrm{~b}$.

TOREZAN, J. M. D. Nota sobre a vegetação da bacia do rio Tibagi. In: A Bacia do Rio Tibagi. Londrina (PR): M.E. Medri, 2002.

TROPPMAIR, H. Biogeografia e Meio Ambiente. $3^{\text {a }}$ Ed. Rio Claro: Unesp, 1989.

TROPPMAIR, H. Ecossistemas e geossistemas do Estado de São Paulo. Boletim de Geografia Teorética, v.13, n.25, p. 27-36, Rio Claro, 1983.

TROPPMAIR, H. Perfil fitoecológico do Estado do Paraná. Boletim de Geografia, v.8, n.1, 1990.

VEADO, R. W. A. \& TROPPMAIR, H. Geossistemas do Estado de Santa Catarina. In: GERARDI, L. H. O. \& MENDES, I. A. (org). Teoria, Técnicas, Espaços e Atividades: temas de Geografia contemporânea. Rio Claro: UNESP-AGETEO, 2001.

Recebido em abril de 2010

Aceito em agosto de 2010

Revista da ANPEGE. v. 6, 2010 (jan./dez.) 